\title{
KRAS mutation is a weak, but valid predictor for poor prognosis and treatment outcomes in NSCLC: A meta-analysis of 41 studies
}

\author{
Wei Pan ${ }^{1,2}$, Yan Yang $^{1}$, Hongcheng Zhu ${ }^{1}$, Youcheng Zhang ${ }^{3}$, Rongping Zhou ${ }^{3}$, \\ Xinchen Sun ${ }^{1}$ \\ ${ }^{1}$ Department of Radiation Oncology, The First Affiliated Hospital of Nanjing Medical University, Nanjing, Jiangsu, P.R. China \\ ${ }^{2}$ Department of Oncology, The Second Hospital of Nanjing Jiangning, Nanjing, Jiangsu, P.R. China \\ ${ }^{3}$ Department of Oncology, Nanjing Jiangning Hospital, Nanjing, Jiangsu, P.R. China
}

Correspondence to: Xinchen Sun, e-mail: starrystyle@hotmail.com

Keywords: non-small cell lung cancer, KRAS mutation, prognosis, EGFR-TKI, meta-analysis

Received: July 30, $2015 \quad$ Accepted: January 13, $2016 \quad$ Published: January 30, 2016

\section{ABSTRACT}

Mutation of oncogene KRAS is common in non-small cell lung cancer (NSCLC), however, its clinical significance is still controversial. Independent studies evaluating its prognostic and predictive value usually drew inconsistent conclusions. Hence, We performed a meta-analysis with 41 relative publications, retrieved from multidatabases, to reconcile these controversial results and to give an overall impression of KRAS mutation in NSCLC. According to our findings, KRAS mutation was significantly associated with worse overall survival (OS) and disease-free survival (DFS) in early stage resected NSCLC (hazard ratio or HR=1.56 and 1.57, 95\% CI 1.39-1.76 and 1.172.09 respectively), and with inferior outcomes of epidermal growth factor receptortyrosine kinase inhibitors (EGFR-TKIs) treatment and chemotherapy (relative risk or $R R=0.21$ and 0.66 for objective response rate or ORR, $95 \% \mathrm{CI}$ 0.12-0.39 and 0.54-0.81 respectively; HR=1.46 and 1.30 for progression-free survival or PFS, 95\%CI $1.23-$ 1.74 and 1.14-1.50 respectively) in advanced NSCLC. When EGFR mutant patients were excluded, KRAS mutation was still significantly associated with worse OS and PFS of EGFR-TKIs (HR=1.40 and 1.35, $95 \%$ CI 1.21-1.61 and 1.11-1.64). Although KRAS mutant patients presented worse DFS and PFS of chemotherapy (HR=1.33 and 1.11, 95\% CI 0.97-1.84 and 0.95-1.30), and lower response rate to EGFR-TKIs or chemotherapy ( $R R=0.55$ and $0.88,95 \% C I \quad 0.27-1.11$ and $0.76-1.02)$, statistical differences were not met. In conclusion, KRAS mutation is a weak, but valid predictor for poor prognosis and treatment outcomes in NSCLC. There's a need for developing target therapies for KRAS mutant lung cancer and other tumors.

\section{INTRODUCTION}

Lung cancer, with NSCLC accounts for $85 \%$ of all cases, is the most common human malignant disease and the leading cause of cancer-related mortality worldwide [1,2]. Early as the beginning of this century, novel molecular targeted agents like EGFR-TKIs represented by gefitinib or erlotinib, which interfere with EGFR signaling, have been proved dramatically effective for selected advanced NSCLC patients with sensitive EGFR mutations [3]. Since then, molecular target therapies provided promising treatment alternatives to surgery, radiation therapy and chemotherapy. Personalized, genotype-directed therapy for NSCLC couldn't be more popular. Besides EGFR, $K R A S$ is the most frequently mutated oncogene in NSCLC (15-20\%) with most cases affect exon 2 and 3 (G12, G13 and Q61). It seemed that KRAS mutation occurs more frequently in lung adenocarcinomas (approximately $30 \%$ ), in the Caucasian population, and in the population with smoking history [4-6].

$K R A S$ mutation was described as a negative prognostic marker for OS and DFS in lung adenocarcinoma more early in 1990 [7]. Not until the last ten years, clinical significance of KRAS mutation in NSCLC has been attracted more and more attention. Although a lot of published studies reported that KRAS 
mutation is associated with poor prognosis and outcomes of EGFR-TKIs treatment [8-11] and chemotherapy [10, 12-15], more than a few independent studies argued that it predicts neither worse prognosis $[8,10-12,14$, 16-28] nor inferior outcomes of EGFR-TKIs treatment or chemotherapy [14, 18, 19, 29-32]. Therefore, we carried out a comprehensively search and review of relevant publications in multi-database. Useful data was extracted and then aggregated by using a meta-analysis methodology to give an overall impression of KRAS mutation in NSCLC.

Moreover, it is accepted that sensitive EGFR mutation predicts benefit from EGFR-TKIs treatment and even from chemotherapy in NSCLC $[8,9,18,19$, 26, 32-34]. Mutations of KRAS and EGFR are common and mutually exclusive in NSCLC [35-37]. Thus EGFR mutation predominantly coexists with wild type $K R A S$, which made us overestimate the prognostic and predictive value of KRAS mutation. Therefore, analyses were reperformed in $E G F R$ wild-type NSCLC to obtain objective and unassertive conclusions.

\section{RESULTS}

\section{Study characteristics and quality assessment}

Based on our search criteria, a total of 41 studies, which enrolled 13,103 KRAS assessable patients with 18 percent $(2,374) K R A S$ mutant positive cases, were eligible for inclusion in the present analyses. The process of selecting publications was presented in Figure 1 and the clinical characteristics of the included studies were listed in Table 1 . All of the studies were published from 2005-2015, consisting of 40 cohort studies [8-31, 34, 35, 38-51] and one randomized controlled trial (RCT)[32]. Thirty studies $[8,9,11-19,21-28,31,35,38,40-43$, 46-48, 51] conducted in Europe and North America, ten studies $[10,20,29,30,32,34,39,44,45,50]$ in Asia, and one study [49] in Latin America. All of the studies focused on NSCLC or lung adenocarcinoma only except one [46] on lung squamous cell carcinoma. Ten studies $[16,20,24,25,29,30,39,43,47,48]$ dealt with stage I-IIIa resected tumors, twenty-nine studies [8, 9, 11-15, $17-19,21-23,26-28,31,34,35,38,40-42,44-46$, 49-51] with stage IIIb-IV unresectable tumors, and two studies $[10,32]$ with all stage tumors. Thirteen studies $[10,12,13,18,29,30,34,35,41,44,46,47,49]$ used a polymerase chain reaction (PCR) or modified PCR method to test gene mutation, while the others used a direct sequencing method. Four studies [12, 13, 38, 45] assessed $K R A S$ mutation in plasma DNA and the others in tumor specimens. In consistent with large-scaled demographic results [6], the majority of $K R A S$ mutation occurs in codon 12 , with G12C the most, occasionally in codon 13 , and rarely in codon 61 . All the studies selected patients randomly without concerning gender or smoking status and most results were adjusted for gender, age, stage and Karnofsky performance score.

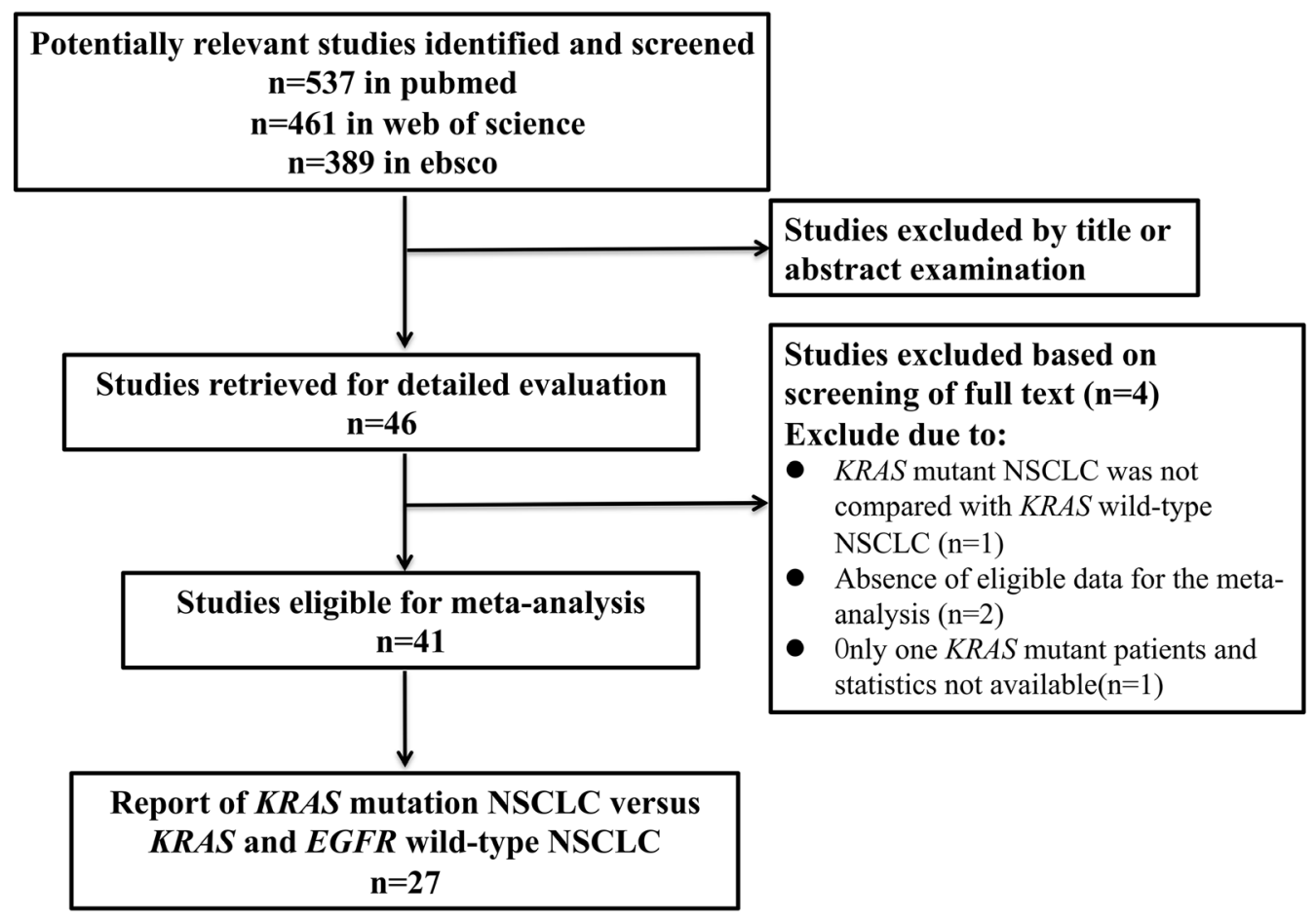

Figure 1: Flow Chart of publication search and selection. 
Table 1: Clinical characteristics of included studies

\begin{tabular}{|c|c|c|c|c|c|c|c|c|c|c|c|c|}
\hline First Author & Year & Race & $\begin{array}{l}\text { Patients } \\
\text { Number }\end{array}$ & $\begin{array}{l}\text { KRAS MUT } \\
\text { Number(\%) }\end{array}$ & $\begin{array}{l}\text { Gene Testing } \\
\text { Method }\end{array}$ & $\begin{array}{l}\text { Specimens } \\
\text { Assessed }\end{array}$ & Pathology & Stage & Treatments & Outcome & $\begin{array}{l}K R A S \text { MUT } \\
\text { Versus }\end{array}$ & $\begin{array}{c}\text { Quality } \\
\text { Score }\end{array}$ \\
\hline William [35] & 2005 & Caucasian & 60 & $9(15.0)$ & PCR & Tumor & $\mathrm{ADC}$ & IIIB-IV & TKI & ORR & WT/WT & 6 \\
\hline David [8] & 2005 & Caucasian & 274 & $55(20.0)$ & Sequencing & Tumor & NSCLC & IIIB-IV & TKI / CT & OS / ORR / PFS & WT/WT & 8 \\
\hline Erminia [9] & 2007 & Caucasian & 70 & $16(22.9)$ & Sequencing & Tumor & NSCLC & IIIB-IV & TKI & ORR / PFS & WT/WT & 8 \\
\hline Oliver [38] & 2007 & Caucasian & 175 & $16(9.1)$ & Sequencing & Plasma & NSCLC & I-IV & Various & OS & WT & 6 \\
\hline Young [29] & 2008 & Asian & 71 & $5(7.0)$ & PCR & Tumor & $\mathrm{ADC}$ & I-III & $\mathrm{R}$ & OS / DFS & WT & 6 \\
\hline Jenifer [16] & 2008 & Caucasian & 296 & $50(16.9)$ & Sequencing & Tumor & $\mathrm{ADC}$ & I-III & $\mathrm{R}$ & OS & WT/WT & 9 \\
\hline Chang-qi [17] & 2008 & Caucasian & 206 & $30(14.6)$ & Sequencing & Tumor & NSCLC & IIIB-IV & TKI & OS / ORR & NA & 9 \\
\hline Takayuki [39] & 2009 & Asian & 254 & 32 (12.6) & Sequencing & Tumor & $\mathrm{ADC}$ & I-III & $\mathrm{R}$ & OS & WT/WT & 9 \\
\hline MILOS [18] & 2009 & Caucasian & 208 & $32(15.4)$ & PCR & Tumor & NSCLC & IIIB-IV & TKI & OS / PFS & WT/WT & 7 \\
\hline David [19] & 2009 & Caucasian & 175 & $41(23.4)$ & Sequencing & Tumor & NSCLC & IIIB-IV & TKI & OS / ORR / PFS & WT/WT & 8 \\
\hline Tetsukan [30] & 2009 & Asian & 168 & $24(14.3)$ & PCR & Tumor & $\mathrm{ADC}$ & I & $\mathrm{R}$ & DFS & WT & 9 \\
\hline Antonio [40] & 2009 & Caucasian & 83 & $16(19.3)$ & Sequencing & Tumor & NSCLC & IIIB-IV & TKI & OS / ORR / PFS & WT/WT & 7 \\
\hline Hui-ping [20] & 2010 & Asian & 156 & $7(4.5)$ & Sequencing & Tumor & NSCLC & I-III & $\mathrm{R}$ & OS & WT/WT & 7 \\
\hline Laura [41] & 2010 & Caucasian & 62 & $12(19.4)$ & PCR & Tumor & $\mathrm{ADC}$ & IIIB-IV & TKI & OS / PFS & WT & 8 \\
\hline Vienna [21] & 2011 & Caucasian & 161 & $11(6.8)$ & Sequencing & Tumor & NSCLC & IIIB-IV & TKI & OS / ORR / PFS & WT/WT & 8 \\
\hline Carlos [12] & 2011 & Caucasian & 308 & $27(8.8)$ & PCR & Plasma & NSCLC & IIIB-IV & $\mathrm{CT}$ & OS / PFS & WT & 8 \\
\hline Hye [10] & 2011 & Asian & 229 & $19(8.3)$ & PCR & Tumor & NSCLC & I-IV & $\begin{array}{l}\mathrm{R} / \mathrm{CT} / \\
\mathrm{TKI}\end{array}$ & $\begin{array}{l}\text { OS / DFS / } \\
\text { ORR / PFS }\end{array}$ & WT/WT & 6 \\
\hline Wolfram [22] & 2011 & Caucasian & 493 & $90(18.3)$ & Sequencing & Tumor & NSCLC & IIIB-IV & TKI & OS / PFS & WT/WT & 9 \\
\hline Vienna [42] & 2012 & Caucasian & 162 & $11(6.8)$ & Sequencing & Tumor & NSCLC & IIIB-IV & TKI & OS / ORR / PFS & WT/WT & 9 \\
\hline Chiara [43] & 2012 & Caucasian & 249 & 46 & Sequencing & Tumor & NSCLC & I-III & $\mathrm{R}$ & DFS & WT/WT & 9 \\
\hline Melissa [23] & 2012 & Caucasian & 1036 & $241(23.3)$ & Sequencing & Tumor & $\mathrm{ADC}$ & IV & $\mathrm{CT} / \mathrm{TKI}$ & OS & WT/WT & 9 \\
\hline Jie [44] & 2012 & Asian & 104 & $9(8.7)$ & PCR & Tumor & NSCLC & IIIB-IV & Various & OS & WT & 6 \\
\hline Giulio [11] & 2012 & Caucasian & 67 & $18(26.9)$ & Sequencing & Tumor & $\mathrm{ADC}$ & IIIB-IV & TKI & OS / ORR / PFS & WT/WT & 7 \\
\hline Jacques [31] & 2012 & Caucasian & 307 & $42(13.7)$ & Sequencing & Tumor & NSCLC & IIIB-IV & TKI & OS / PFS & WT/WT & 7 \\
\hline Seung [45] & 2013 & Asian & 57 & $14(24.6)$ & Sequencing & Plasma & NSCLC & IIIB-IV & TKI / BSC & OS / ORR & WT & 8 \\
\hline Anneli [13] & 2013 & Caucasian & 246 & $43(17.5)$ & PCR & Plasma & NSCLC & IIIB-IV & $\mathrm{CT}$ & OS / ORR / PFS & WT & 8 \\
\hline Ondrej [46] & 2013 & Caucasian & 215 & $16(7.4)$ & PCR & Tumor & $\mathrm{SCC}$ & IIIB-IV & TKI & OS / PFS & WT & 7 \\
\hline Ji-lin [32] & 2013 & Asian & 1935 & $98(5.1)$ & Sequencing & Tumor & $\mathrm{ADC}$ & I-IV & $\begin{array}{l}\mathrm{R} / \mathrm{TKI} / \\
\mathrm{CT}\end{array}$ & $\begin{array}{l}\text { OS / DFS / } \\
\text { ORR / PFS }\end{array}$ & WT/WT & $3^{*}$ \\
\hline Jong-Mu [34] & 2013 & Asian & 484 & $39(8.1)$ & PCR & Tumor & $\mathrm{ADC}$ & IIIB-IV & TKI / CT & OS / ORR / PFS & WT/WT & 9 \\
\hline Frances [25] & 2013 & Caucasian & 1543 & $300(19.4)$ & Sequencing & Tumor & NSCLC & I-III & $\mathrm{R}$ & OS / DFS & WT & 9 \\
\hline Gerald [26] & 2013 & Caucasian & 368 & $110(29.9)$ & Sequencing & Tumor & NSCLC & IIIB-IV & TKI & OS & WT/WT & 6 \\
\hline Wouter [14] & 2013 & Caucasian & 161 & $60(37.3)$ & Sequencing & Tumor & $\mathrm{ADC}$ & IIIB-IV & CT & OS / ORR / PFS & WT & 8 \\
\hline Giulio [15] & 2014 & Caucasian & 204 & $77(37.7)$ & Sequencing & Tumor & $\mathrm{ADC}$ & IIIB-IV & CT & OS / ORR / PFS & WT/WT & 9 \\
\hline Marianna [27] & 2014 & Caucasian & 108 & $39(36.1)$ & Sequencing & Tumor & NSCLC & IIIB-IV & CT & OS / ORR / PFS & WT/WT & 9 \\
\hline Mihaly [28] & 2014 & Caucasian & 1125 & $361(32.1)$ & Sequencing & Tumor & $\mathrm{ADC}$ & IIIB-IV & CT & OS / ORR / PFS & WT/WT & 9 \\
\hline Mark [24] & 2014 & Caucasian & 230 & $39(17.0)$ & Sequencing & Tumor & $\mathrm{ADC}$ & I-III & $\mathrm{R}$ & OS / DFS & WT/WT & 8 \\
\hline Benjamin [47] & 2014 & Caucasian & 312 & $127(40.7)$ & PCR & Tumor & $\mathrm{ADC}$ & I & $\mathrm{R}$ & OS / DFS & WT/WT & 8 \\
\hline Ernest [48] & 2015 & Cacasian & 179 & $85(47.5)$ & Sequencing & Tumor & $\mathrm{ADC}$ & I-III & $\mathrm{R}$ & OS / DFS & WT & 8 \\
\hline Alma [49] & 2015 & Other & 225 & $40(17.8)$ & PCR & Tumor & NSCLC & IIIB-IV & TKI / CT & OS / ORR / PFS & WT & 8 \\
\hline Shigehiro [50] & 2015 & Asian & 119 & $16(13.4)$ & Sequencing & Tumor & $\mathrm{ADC}$ & IIIB-IV & CT & OS / ORR / PFS & WT/WT & 8 \\
\hline Eliana [51] & 2015 & Caucasian & 218 & $51(23.4)$ & Sequencing & Tumor & NSCLC & IIIB-IV & TKI / CT & OS / ORR / PFS & WT/WT & 8 \\
\hline
\end{tabular}

MUT, mutation; NSCLC, non-small cell lung cancer; ADC lung adenocarcinoma; SCC, lung squamous cell carcinoma;

CT, chemotherapy; R, surgical resection; WT, KRAS wild-type; WT/WT, KRAS and EGFR wild-type. * randomized controlled trial was evaluated based on Jadad Scale. 
The quality of cohort study was assessed using the Newcastle-Ottawa Scale (NOS) on three perspectives: patient selection, comparability of groups, and assessment of outcome. Full score is nine stars, and a study with more stars was considered to be of higher quality. Quality scores of 40 cohort studies ranged from six to nine with a median score of eight. The quality of RCT was assessed using the Jadad Scale on three perspectives: randomization, double blinding, withdraws and dropouts. Full score is five points, and a study with score no less than three points is defined the high-quality study. The only included RCT gained a score of three points. No "poor quality" study was found and all of the studies were considered acceptable for inclusion in the present meta-analysis. The study specific scores were summarized in Table S1.

\section{$K R A S$ mutation and clinical features}

Data of clinical features stratified by KRAS mutational status was reported in 25 studies [9, 10, 12-17, 21, 23, 24, 26-28, 30, 32, 34, 39, 41, 44-48, 50]. Data was extracted from individual studies and then aggregated. The result indicated that KRAS mutation occurs more frequently in lung adenocarcinoma $(R R=1.16 \mathrm{p}=0.016)$, and in former or current smokers $(R R=1.13 \mathrm{p}=0.017)$, but not in male gender $(\mathrm{RR}=1.07 \mathrm{p}=0.142)$ (Table $\mathrm{S} 2)$. Reported gene mutation rate ranged from $4.4 \%$ to $24.5 \%$ in the Asians and from $6.7 \%$ to $47.4 \%$ in the Caucasians. Additionally, an increased incidence of presence of stage IV disease and distant metastasis in KRAS mutant patients was reported in several studies [27, 50].

\section{Prognostic and predictive value of $K R A S$ mutation in unselected NSCLC}

Thirty-seven studies [8, 10-29, 31, 32, 34, 38-42, 44-51] provided HRs for OS comparing KRAS mutant NSCLC with KRAS wild-type NSCLC. Pooled HR was 1.56 for OS $(95 \% \mathrm{CI} 1.39-1.76, \mathrm{p}=0.00)$ (Figure $2 \mathrm{~A})$, indicating a significantly worse survival for $K R A S$ mutant patients. Significant heterogeneity among studies $\left(I^{2}=54.6 \%, \mathrm{p}=0.00\right)$ and publication bias (Begg's test $\mathrm{p}=0.053$, Egger's test $\mathrm{p}=0.014$ ) (Figure 2B) was detected. Meta-regression analysis showed that only race (adjusted $\mathrm{R}^{2}=77.12 \%, \mathrm{p}=0.00$ ) might contribute to the heterogeneity, but not other factors such as disease stage $(p=0.885)$, pathology $(p=0.454)$, gene mutation testing method $(\mathrm{p}=0.029)$ and specimens (plasma/tumor foci) for mutation assessment $(p=0.560)$. As shown in Figure 2A, subgroup analysis according to race showed that $K R A S$ mutation is a more powerful negative prognostic factor for $\mathrm{OS}$ in the Asians $(\mathrm{HR}=2.39$ with $95 \%$ CI $1.97-2.90$ and $\mathrm{p}=0.00, I^{2}=0.0 \%$ and $\mathrm{p}=0.648$ for heterogeneity) than in the Caucasians ( $\mathrm{HR}=1.37$ with $95 \%$ CI $1.24-1.51$ and $\mathrm{p}=0.00, I^{2}=30.5$ and $\mathrm{p}=0.066$ for heterogeneity).
Nine studies [10, 24, 25, 29, 30, 32, 43, 47, 48] dealt with stage I-IIIa resected NSCLC and provided HRs for DFS comparing $K R A S$ mutant tumors with $K R A S$ wild-type tumors. All cases received R0 resection and lobectomies were performed mostly. Pooled HR was 1.57 for DFS (95\% CI 1.17-2.09, p=0.002) (Figure 2D), indicating an increased hazard for disease recurrence after tumor resection for KRAS mutant patients. Neither significant heterogeneity $\left(I^{2}=47.6 \%, \mathrm{p}=0.054\right)$ nor publication bias (Begg's test $p=0.754$, Egger's test $p=0.062$ ) (Figure $2 E$ ) was detected. However, meta-regression analysis showed that significant heterogeneity did exist between two races (adjusted $\mathrm{R}^{2}=-85.65 \%, \mathrm{p}=0.042$ ). Similarly, subgroup analysis according to race showed that $K R A S$ mutation is a more powerful negative prognostic factor for DFS in the Asians $\left(\mathrm{HR}=2.59,95 \% \mathrm{CI} 1.55-4.30\right.$ and $\mathrm{p}=0.00, I^{2}=0.0 \%$ and $p=0.847$ for heterogeneity) than in the Caucasians $\left(\mathrm{HR}=1.31,95 \%\right.$ CI $0.99-1.73$ and $\mathrm{p}=0.057, I^{2}=42.7 \%$ and $p=0.137$ for heterogeneity) (Figure 2D).

Eighteen studies [9-11, 17-19, 21, 22, 31, 32, 34, $35,40-42,46,49,51]$ investigated outcomes (response rate or PFS) of EGFR-TKIs treatment in stage IIIb-IV unresectable NSCLC comparing KRAS mutant tumors with $K R A S$ wild-type tumors. Either gefitinib or erlotinib was administered in standard dosage as first to threeline treatment. The total ORR (complete response or $\mathrm{CR}+$ partial response or PR) was $2.5 \%(6 / 237)$ in $K R A S$ mutant patients and 34.0\% (499/1469) in KRAS wild-type patients. Pooled RR was 0.21 for ORR (95\% CI 0.12$0.39, \mathrm{p}=0.00$ ) (Figure 3A) while pooled HR was 1.46 for PFS (95\% CI 1.23-1.74, p=0.0) (Figure 3D), indicating a significant lower response rate and shorter remission period of EGFR-TKIs treatment for KRAS mutant patients. Neither significant heterogeneity $\left(I^{2}=0.0 \%, \mathrm{p}=0.876\right.$ and $I^{2}=44.3 \%, \mathrm{p}=0.033$ respectively) nor publication bias (Begg's test $\mathrm{p}=0.502$, Egger's test $\mathrm{p}=0.086$ and Begg's test $\mathrm{p}=0.06$, Egger's test $\mathrm{p}=0.053$ respectively) (Figure $3 \mathrm{~B}$ and $3 \mathrm{E})$ was detected. Meta-regression analysis showed that neither race $(\mathrm{p}=0.440)$ nor gene mutation testing method $(p=0.807)$ contributes significantly to the heterogeneity.

Thirteen studies $[8,10,12-15,27,32,34,41,49-$ $51]$ investigated outcomes of chemotherapy in stage IIIbIV unresectable NSCLC comparing KRAS mutant tumors with $K R A S$ wild-type tumors. Platinum-based doublet was used for first to second-line treatment. The total ORR was $21.1 \%$ (82/389) in KRAS mutant patients and 32.9\% (486/1477) in $K R A S$ wild-type patients. Pooled RR was 0.66 for ORR (95\% CI 0.54-0.81, $\mathrm{p}=0.00)$ (Figure 4A) while pooled HR was 1.30 for PFS (95\% CI 1.14-1.50, $\mathrm{p}=0.0$ ) (Figure 4D), indicating a significant lower response and shorter remission period of chemotherapy for $K R A S$ mutant patients. Neither significant heterogeneity ( $I^{2}=0.0 \%, \mathrm{p}=0.949$ and $I^{2}=23.8 \%, \mathrm{p}=0.203$ respectively) nor publication bias (Begg's test $\mathrm{p}=0.755$, Egger's test $\mathrm{p}=0.506$ and Begg's test $\mathrm{p}=0.583$, Egger's test $\mathrm{p}=0.419$ respectively) (Figure $4 \mathrm{~B}$ and $4 \mathrm{E}$ ) was detected. 


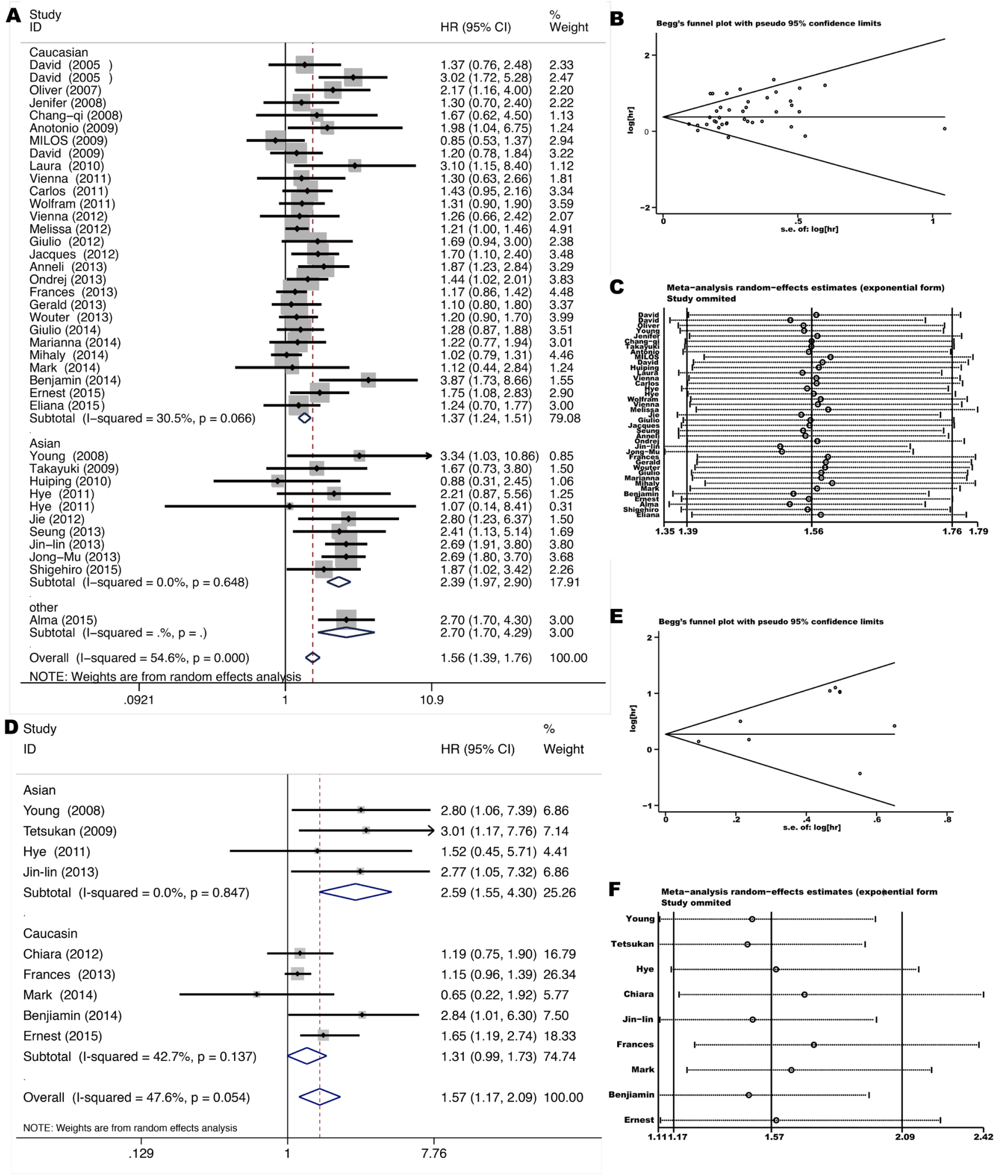

Figure 2: Forrest plot A, D. with influence analysis $\mathbf{C}, \mathbf{F}$. of hazard ratio for overall survival and disease-free-survival comparing $K R A S$ mutant patients with $K R A S$ wild-type patients. Begg's funnel plot of enrolled studies for estimating the hazard ratio for overall survival B. and disease-free-survival $\mathbf{E}$. 
Meta-regression analysis showed that neither race $(p=0.736)$ nor gene mutation testing method $(p=0.389)$ contributes significantly to the heterogeneity.

\section{Prognostic and predictive value of $K R A S$ mutation in EGFR wild-type NSCLC}

Additionally, twenty-seven studies [8-11, 15, 16, 18-24, 26-28, 31, 32, 34, 35, 39, 40, 42, 43, 47, 50, 51] including 9,383 both $K R A S$ and $E G F R$ assessable patients investigated the prognostic and predictive value of $K R A S$ mutation in $E G F R$ wild-type NSCLC. Although mutations of $K R A S$ and $E G F R$ were mutually exclusive in most cases [35-37], presence of both gene mutations could be seen occasionally [18, 34, 47].

As shown in Figure 5A, pooled HR was 1.40 for OS (95\% CI 1.21-1.61, p=0.0) based on 21 studies [10, 11, 15, $16,18-20,22-24,26-28,31,32,34,39,42,47,50,51]$ comparing KRAS mutant NSCLC with KRAS and EGFR wild-type NSCLC, indicating a significant worse survival for $K R A S$ mutant patients. Significant heterogeneity among studies $\left(I^{2}=57.3 \%, \mathrm{p}=0.0\right)$ but not publication
A Study

ID

William (2005)

Erminia (2007)

Chang-qi (2008)

Antonio (2009)

David (2009)

Vienna (2011)

Hye (2011)

Vienna (2012)

Giulio (2012)

Jin-lin (2013)

Jong-Mu (2013)

Alma (2015)

Eliana (2015)

Overall $(\mathrm{I}-$ squared $=0.0 \%, \mathrm{p}=0.876)\langle$

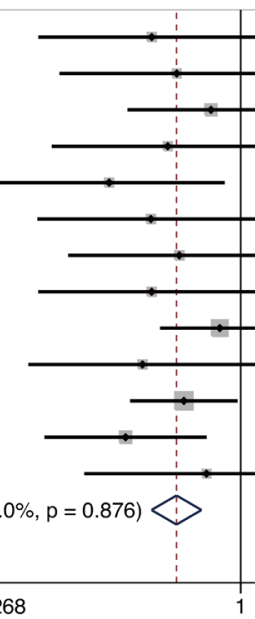

$\%$
RR $(95 \% \mathrm{Cl}) \quad$ Weight

$0.12(0.01,1.80) 4.85$

$0.22(0.01,3.58) 4.54$

$0.49(0.07,3.62) 8.98$

$0.17(0.01,2.81) 4.64$

$0.04(0.00,0.68) 4.68$

$0.12(0.01,1.77) 4.84$

$0.23(0.02,3.29) 5.06$

$0.12(0.01,1.80) 4.84$

$0.60(0.14,2.54) 17.45$

$0.09(0.01,1.46) 4.79$

$0.26(0.07,0.93) 21.65$

$0.06(0.01,0.44) 9.50$

$0.44(0.02,8.23) 4.18$

$0.21(0.12,0.39) 100.00$



C Meta-analysis fixed-effects estimates (exponential form)

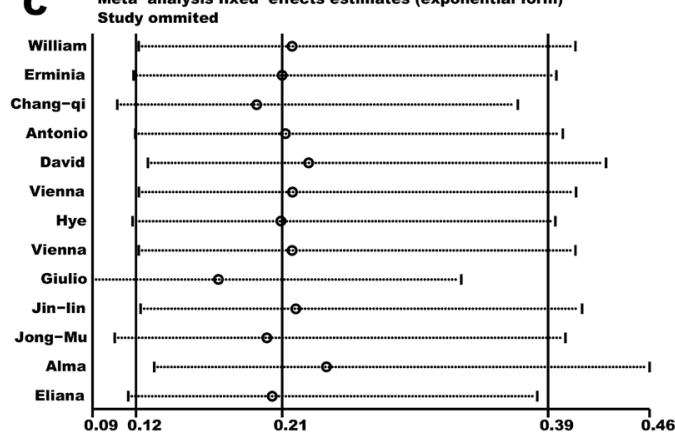

D Study ID

$\mathrm{HR}(95 \% \mathrm{Cl}) \quad$ Weight
David (2005)

Erminia (2007)

Antonio (2009)

MILOS (2009)

David (2009)

Vienna (2011)

Wolfram (2011)

Vienna (2012)

Giulio (2012)

Jacques (2012)

Ondrej (2013)

Jin-lin (2013)

Jong-Mu (2013)

Alma (2015)

Eliana (2015)

Overall (I-squared $=44.3 \%, p=0.033$ )

NOTE: Weights are from random effects analysis
$1.71(1.03,2.83) 7.00$

$2.14(1.20,3.82) 5.93$

$2.52(1.68,6.36) 4.91$

$1.33(0.62,2.83) 4.05$

$1.00(0.27,4.07) 1.52$

$3.96(1.58,9.97) 2.98$

$1.50(1.06,2.12) 10.11$

$1.83(0.84,4.02) 3.86$

$1.92(1.10,3.37) 6.19$

$1.20(0.80,1.80) 8.83$

$1.54(0.90,2.64) 6.50$

$0.78(0.50,1.21) 8.11$

$1.29(0.96,1.71) 11.50$

$1.70(1.10,2.80) 7.65$

$1.01(0.74,1.39) 10.85$

$1.46(1.23,1.74) 100.00$

9.97

Figure 3: Forrest plot of relative ratio for objective response rate A. and hazard ratio for progression-free-survival $\mathbf{D}$. with influence analysis C, F. comparing KRAS mutant patients with KRAS wild-type patients treated with EGFR TKIs. Begg's funnel plot of enrolled studies for estimating the relative ration for overall response B. and hazard ratio for progression-free-survival $\mathbf{E}$. 
bias (Begg's test $\mathrm{p}=0.866$, Egger's test $\mathrm{p}=0.486$ ) (Figure S1A) was detected. Similarly, meta-regression analysis showed that only races (adjusted $\mathrm{R}^{2}=95.14 \%, \mathrm{p}=0.0$ ) might contribute to the heterogeneity. Subgroup analysis according to races showed that $K R A S$ mutation impairs survival more seriously in the Asians $(\mathrm{HR}=2.30$ with $95 \%$ CI $1.84-2.88$ and $\mathrm{p}=0.0, I^{2}=6.1 \%$ and $\mathrm{p}=0.381$ for heterogeneity) than in the Caucasians ( $\mathrm{HR}=1.22$ with $95 \%$ CI $1.11-1.33$ and $\mathrm{p}=0.00, I^{2}=0.0 \%$ and $\mathrm{p}=0.653$ for heterogeneity) (Figure 5A).
As shown in Figure 5B, pooled HR was 1.33 for DFS (95\% CI 0.97-1.84, $\mathrm{p}=0.076)$ based on six studies $[10,24,25,32,43,47]$ conducted in stage I-IIIa resected NSCLC comparing KRAS mutant tumors with KRAS and EGFR wild-type tumors, exhibiting an insignificant trend towards increased hazard for disease recurrence after tumor resection for $K R A S$ mutant patients. Neither significant heterogeneity $\left(I^{2}=36.0 \%, \quad \mathrm{p}=0.167\right)$ nor publication bias (Begg's test $\mathrm{p}=1.00$, Egger's test $\mathrm{p}=0.334$ ) (Figure S1B) was detected. Meta-regression analysis

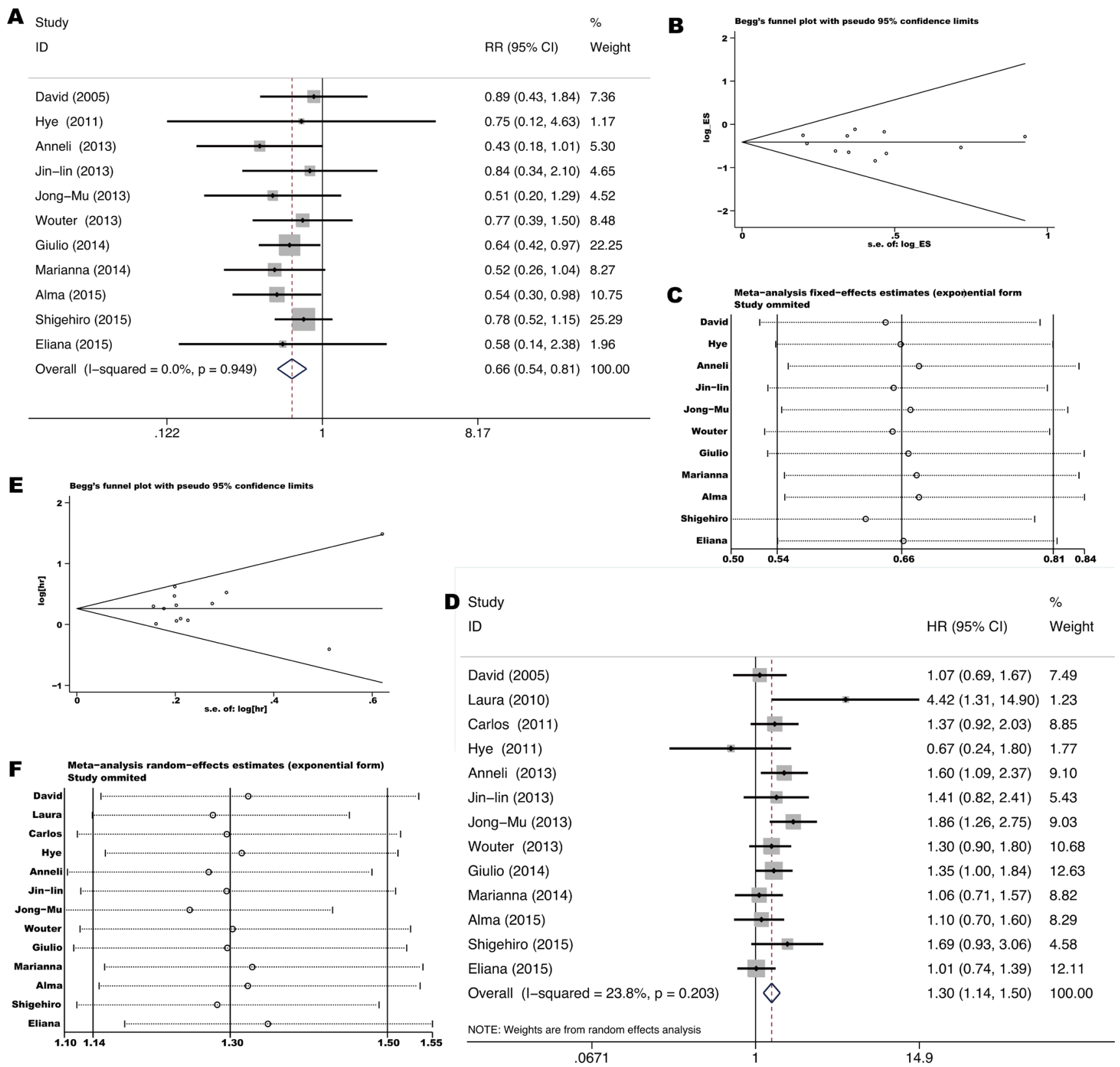

Figure 4: Forrest plot of relative ratio for objective response rate A. and hazard ratio for progression-free-survival $\mathbf{D}$. with influence analysis C, F. comparing $K R A S$ mutant patients with $K R A S$ wild-type patients treated with chemotherapy. Begg's funnel plot of enrolled studies for estimating the relative ration for overall response B. and hazard ratio for progression-free-survival $\mathbf{E}$. 
showed that neither race $(p=0.242)$ nor gene mutation testing method $(p=0.189)$ contributes significantly to the heterogeneity.

The total ORR to EGFR-TKIs was 2.3\% (4/175) in KRAS mutant patients and 13.6\% (101/740) in KRAS and EGFR wild-type patients based on 14 studies [9-11, 18, $19,21,22,31,32,34,35,40,42,51]$ conducted in stage IIIb-IV unresectable NSCLC. As shown in Figure 6A and
6B, pooled RR was 0.55 for ORR (95\% CI 0.27-1.11, $\mathrm{p}=0.095)$ while pooled HR was 1.35 for PFS $(95 \% \mathrm{CI}$ 1.11-1.64, $\mathrm{p}=0.002$ ), exhibiting an insignificant trend towards lower response but significant shorter remission period of EGFR-TKIs treatment for KRAS mutant patients. Neither significant heterogeneity $\left(I^{2}=0.0 \%, \mathrm{p}=0.996\right.$ and $I^{2}=42.0 \%, \mathrm{p}=0.069$ respectively) nor publication bias (Begg's test $p=1.00$, Egger's test $p=0.109$ and Begg's



Figure 5: Forrest plot of hazard ratio for overall survival A. and disease-free-survival B. comparing $K R A S$ mutant patients with $K R A S$ and EGFR wild-type patients. 
test $\mathrm{p}=0.436$, Egger's test $\mathrm{p}=0.256$ respectively) (Figure S1C and S1D) was detected. Meta-regression analysis showed that neither race $(\mathrm{p}=0.159)$ nor gene mutation testing method $(\mathrm{p}=0.801)$ contributes significantly to the heterogeneity.

The total ORR to chemotherapy was $35.8 \%$ $(138 / 385)$ in KRAS mutant patients and $45.1 \%(381 / 845)$ in $K R A S$ and $E G F R$ wild-type patients based on eight studies $[8,10,15,27,28,32,50,51]$ conducted in stage IIIb-IV unresectable NSCLC. As shown in Figure 6C and 6D, pooled RR was 0.88 for ORR ( $95 \%$ CI $0.76-1.02, p=0.083$ ) while pooled HR was 1.11 for PFS (95\% CI $0.95-1.30$, $\mathrm{p}=0.186$ ), exhibiting an insignificant trend towards lower response and shorter remission period of chemotherapy for KRAS mutant patients. Neither significant heterogeneity ( $I^{2}=1.6 \%, \mathrm{p}=0.340$ and $I^{2}=18.0 \%, \mathrm{p}=0.286$ respectively) nor publication bias (Begg's test $\mathrm{p}=0.902$, Egger's test $p=0.3$ and Begg's test $p=0.764$, Egger's test $p=0.493$ respectively) (Figure S1E and S1F) was detected. Metaregression analysis showed that race $(\mathrm{p}=0.509)$ doesn't contribute significantly to the heterogeneity.

\section{Sensitivity analyses}

In general, no individual publication was found to be significantly biasing the results (Figure $2 \mathrm{C}, 2 \mathrm{~F}, 3 \mathrm{C}, 3 \mathrm{~F}$, $4 \mathrm{C}, 4 \mathrm{~F}$ and Figure S2A-D), but the associations between $K R A S$ mutation with lower response rate and shorter remission period of chemotherapy in EGFR wild-type NSCLC were affected after the data set of Mihaly [28] was removed (Figure S2E, S2F). The associations shifted from statistically insignificant to significant with Mihaly et al.'s study excluded. However, this study enrolled the most patients assessed for outcomes of chemotherapy and gained a high quality score of nine stars, therefor it's unreasonable to role out this study for analyses. The sensitivity analyses showed that the cumulative results are stable.

\section{DISCUSSION}

The KRAS oncogene together with HRAS and NRAS encode a family of membrane-bound $21 \mathrm{kd}$ guanosine triphosphate binding proteins (GTPs) that

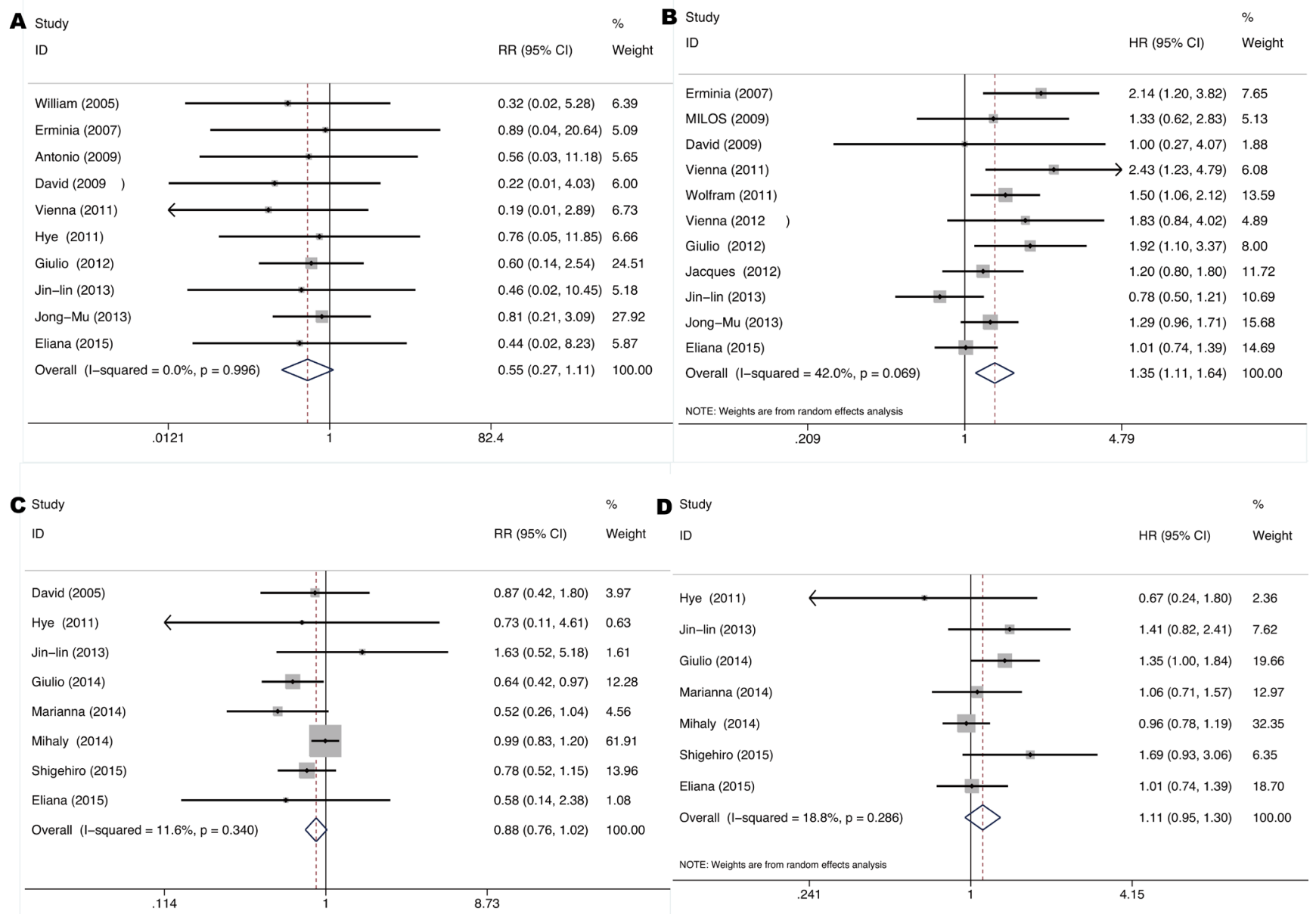

Figure 6: Forrest plot of relative ratio for objective response rate $\mathbf{A}, \mathbf{C}$. and hazard ratio of progression-free-survival $\mathbf{B}, \mathbf{D}$. comparing $K R A S$ mutant patients with KRAS and $E G F R$ wild-type patients treated with EGFR TKIs and chemotherapy respectively. 
regulate cell growth, differentiation, and apoptosis by interacting with multiple signaling including mitogenactivated protein kinase (MAPK), signal transducer and activator of transcription (STAT), and phosphoinositide 3-kinase (PI3K) signaling cascades [52]. KRAS gene has been found frequently mutated in human tumors such as large intestine, lung and pancreas. Almost all KRASmutant cases affect exon 2 and 3 (G12, G13 and Q61), which impair the deactivation circuit of RAS proteins, thereby causing sustained activation of RAS signaling [53]. Meanwhile RAS is the most important downstream effector of EGFR, therefore sensitive mutation of $K R A S$ gene might attenuate, even abolish the treatment efficacy of anti-EGFR agents such as EGFR-TKIs and EGFR monoclonal antibody (EGFR mAb). It is true that the benefit of cetuximab or panitumumab, two well-known EGFR mAb approved by FDA, is restricted to patients with $K R A S$ wild-type colorectal cancer, and only this subset of patients should receive these agents [54]. Although KRAS is the most common mutated oncogene in NSCLC, its clinical significance is yet under debate. Should we test for it, and does it matter? Is $K R A S$ testing necessary before EGFR-TKIs treatment?

The present meta-analysis with newest and largest quantity of relevant publications confirmed that KRAS mutation is significantly associated with worse OS $(\mathrm{HR}=1.56)$ and DFS $(\mathrm{HR}=1.57)$, and also with inferior ORR $(\mathrm{RR}=0.21$ and 0.66 for TKI and chemotherapy respectively) and PFS ( $\mathrm{HR}=1.46$ and 1.30 respectively) of EGFR-TKIs treatment or chemotherapy, compared with $K R A S$ wild-type NSCLC. While analyzing the association between $K R A S$ mutation with OS, significant publication bias was detected by Egger's test $(p=0.014)$. Thereby, a "trim and fill" method was applied. Elven hypothetical negative unpublished studies were imputed to produce a symmetrical funnel plot (Figure S3). The pooled analysis incorporating the hypothetical studies continued to show a statistically significant association between KRAS mutation and worse survival $(\mathrm{HR}=1.31$, 95\% CI 1.141.50 and $\mathrm{p}=0.00)$. Céline et al. [55] reported a significant worse survival $(\mathrm{HR}=1.35,95 \% \mathrm{CI} 1.16-1.56)$ of $K R A S$ mutant NSCLC compared with KRAS wild-type NSCLC based on a meta-analysis of 28 studies early in 2004. The reported HR for OS was quit similar to ours, however, no significant survival hazard was observed in the subgroup analysis of nine studies using an immunohistochemistry (IHC) method to test RAS alternation ( $\mathrm{HR}=1.08,95 \% \mathrm{CI}$ $0.86-1.34)$. Furthermore, none of the 28 studies used a direct sequencing method, which is a "gold standard" for gene testing and not spreading to clinical application until the last decade. On the contrary, none of the 41 studies included in the present meta-analysis used an IHC method. Instead, more than half of the included studies used a direct sequencing method. As more included studies, more enrolled cases and more developed gene testing method, our results are more reliable.
Resistance to EGFR-TKIs treatment for KRAS mutant NSCLC was also reported in other two metaanalysis conducted by Chen et al. [56] and Min et al. [57]. The reported pooled RR for ORR was 0.29 (95\% CI 0.18 0.47 ) in Chen's study and 0.21 (95\% CI $0.12-0.39)$ in ours while the reported pooled HR for PFS was $1.86(95 \%$ CI 1.51-2.29) in Min's study and 1.46 (95\% CI 1.23-1.74) in ours, showing highly consistent results among studies. Meanwhile, the present meta-analysis included more publications and presented more accurate confidence interval. Resistance to chemotherapy for $K R A S$ mutant NSCLC was also reported by another meta-analysis [58]. The reported odds ratio (OR) was 0.67 (95\% CI 0.50-0.88) for ORR with statistical significance and 0.75 (95\% CI 0.54-1.04) for 6 month and 1-year PFS rate but without statistical significance. Only first-line chemotherapy was evaluated. We doubt that HR might be more suitable than OR for analyzing PFS, which displayed an abnormal distribution. Our results showed both significant inferior ORR ( $\mathrm{RR}=0.67,95 \%$ CI $0.50-0.88)$ and PFS $(\mathrm{HR}=1.30$, 95\% CI 1.14-1.50) for the KRAS mutant patients.

Additionally, we noticed that $K R A S$ mutation impairs OS and DFS more obviously in the Asians $(\mathrm{HR}=2.39$ and 2.59 respectively) than in the Caucasians $(\mathrm{HR}=1.37$ and 1.31 respectively), which is not reported elsewhere. It is believed that KRAS mutation subtypes have diverse prognosis and respond differently to chemotherapy or EGFR-TKIs [15, 25, 28, 47, 48, 59]. The author speculated that different spectrum of $K R A S$ mutation subtypes, especially increased proportion of G13, G12D and G12V in the Asians, might be partly responsible for the different hazard ratio between two races. Secondly, there were more KRAS wild-type cases than KRAS mutant cases enrolled in studies. This unbalanced situation was more obviously in studies conducted in Asia, which might exaggerate the HRs for OS and DFS in the Asians. More detailed mechanisms need to be exploited in future fundamental research focused on divergence of RAS signal transduction between two races.

Besides $K R A S$, oncogene $E G F R$ is also frequently mutated in NSCLC, which predicts dramatic benefits from EGFR-TKIs treatment [3, 8, 17-20, 23, 31], and even from chemotherapy [32,49]. Mutations of $K R A S$ and $E G F R$ are generally mutually exclusive in NSCLC, i.e. most $E G F R$ mutations were existed in $K R A S$ wildtype patients, which might bias the results toward an overestimation of the prognostic and predictive value of $K A S$ mutation. Thus, we carried out further analyses in $E G F R$ wild-type NSCLC to draw a more objective conclusion of clinical significance of $K R A S$ mutation. While compared with $K R A S$ and $E G F R$ wild-type NSCLC, the prognostic and predictive value of $K R A S$ mutation did decreased. Pooled HR decreased from 1.56 and 1.57 to 1.40 and 1.33 for OS and DFS respectively, yet statistically significant for OS $(\mathrm{p}=0.0)$ but not for DFS $(\mathrm{p}=0.076)$. Similarly, KRAS mutation impaired 
OS and DFS (without statistical significance, data not shown) more seriously in the Asians. Pooled RR for ORR increased from 0.21 and 0.66 to 0.55 and 0.88 for EGFR-TKIs treatment and chemotherapy respectively. No statistical significances were observed $(p=0.095$ and 0.813 respectively). Pooled HR for PFS decreased from 1.46 and 1.30 to 1.35 and 1.11 for EGFR-TKIs treatment and chemotherapy respectively. Statistical significance was observed in EGFR-TKIs treatment $(p=0.002)$, but not in chemotherapy $(p=0.186)$. Although associations of KRAS mutation with inferior treatment outcomes turned out to be statistically insignificant, the results seemed unstable. Sensitivity analyses showed that the associations of $K R A S$ mutation with inferior chemotherapy outcomes were significantly affected after Mihaly et al.'s study was removed. It is noteworthy that there were fewer studies evaluating the associations of $K R A S$ mutation with treatment outcomes in EGFR wildtype NSCLC. Besides, obvious trends towards inferior treatment outcomes and borderline confidence intervals were observed, the author speculated that KRAS mutation is still a valid predictor for poor treatment outcomes in EGFR wild-type NSCLC with more publications to be included. However, its prognostic and predictive value is not so remarkable as it was greatly affected by exclusion of EGFR mutant patients and the HRs for OS, DFS and PFS were no more than two fold. Actually only NSCLC patients with sensitive EGFR mutation are recommend to first line EGFR-TKIs treatment according to NCCN Guidelines. Based on the notion that mutations of $E G F R$ and $K R A S$ are generally mutually exclusive, a very few KRAS mutant patients are subjected to EGFR-TKIs treatment. Therefore $K R A S$ testing is of limited value to optimize the use of EGFRTKIs in clinic compared to EGFR testing.

Despite our efforts in performing a comprehensive and accurate analysis, yet several limitations should be taken into consideration when interpreting the findings. Firstly, fewer studies assed the predictive and prognostic value of $K R A S$ mutation in EGFR wild-type NSCLC. Thus borderline significant associations of $K R A S$ mutation with inferior treatment outcomes were observed. Secondly, the present study is a univariate analysis. Although several factors such as race, stage, gene testing method and EGFR mutational status were taken into consideration, other factors such as $K R A S$ mutation subtypes, other gene mutational status as $A L K$ rearrangement $[10,15]$ and $P I K 3 C A$ mutation [21, $42,46,60]$, performance status and smoking status should not be neglected in the analysis with more available data provided in the future studies. Lastly, it is noteworthy that $K R A S$ mutation, and even subtype-specific $K R A S$ mutations, responds differently to different chemotherapeutics [34, 61]. Therefore, associations between subtype-specific KRAS mutations and responses to specific chemotherapeutics should be strictly exploited in future studies.
In conclusion, KRAS mutation is a weak, but valid predictor for poor prognosis and treatment outcomes for surgical resection, EGFR-TKIs treatment or chemotherapy. Its prognostic and predictive value is greatly impaired when EGFR mutant patients were excluded. One thing for sure is that it closely related to a worse survival irrespective of EGFR mutational status especially for the Asians. So far, no effective treatment method direct targeting mutant $K R A S$ gene has been approved in clinic. Agents interrupting RAS signaling such as $M E K$ inhibitor [62-64] or miR-126 [65] seemed selective effective for $K R A S$ mutant tumors, which could be utilized for the development of target therapy for $K R A S$ mutant tumors and might overcome the survival hazard induced by $K R A S$ mutation.

\section{MATERIALS AND METHODS}

\section{Publication search and selection}

The identification of potential relevant studies was performed through a systemic search in PubMed, Embase and Web of Science databases using the following keywords "lung cancer", "non-small cell lung cancer" or "NSCLC" and "KRAS". The latest search was updated on September 2015. Bibliographies of eligible studies, review articles and other relevant publications were also reviewed to identify all potential studies.

A study had to fulfill the following criteria: (1) to deal with non-small cell lung cancer (any stage); (2) to stratified by $K R A S$ mutational status; (3) to assess the correlation between KRAS mutation and survival or treatment outcome (surgery, EGFR-TKIs, platinum-based chemotherapy); (4) to have been published as a full paper in the English language and in the last ten years (20052015). The studies were excluded from the analysis if any of the cases occurred: (a) EGFR-TKIs and platinum-based chemotherapy were used as neo-adjuvant treatment; (b) critical information was missing or could not be obtained by our repeated quests.

\section{Data extraction}

Two investigators (Wei Pan and Yan Yang) independently screened the studies and extracted the data from included studies by using standard data-abstraction forms. Disagreements were resolved through discussion with another investigator (Hongcheng Zhu). For each study, the following characteristics and information were collected: first author, year of publication, number of patients assessed for $K R A S$ gene and number of patients bearing $K R A S$ mutation gene, gene mutation detection method, ethnicity, pathology, clinical stage and data linking $K R A S$ mutation to treatment outcomes (i.e., $\mathrm{CR}+\mathrm{PR}, \mathrm{SD}, \mathrm{PD}$, and PFS). If a direct report of 
HR and 95\% CI was not available, the total number of events, the number of patients at risk in each group and the log-rank statistic or its P-value was used to allow for an approximation of the HR estimate. If above parameters were yet unavailable, estimated value was derived indirectly from Kaplan-Meier curves using the methods described by Tierney et al. [66]. Survival rates on Kaplan-Meier curves were read by Engauge Digitizer version 4.1 (http://digitizer.sourceforge.net), and then the data read from the curves were entered in the calculation spreadsheet appended to Tierney's paper.

\section{Statistical methods}

We extracted relative risks (RRs) with its $95 \% \mathrm{CIs}$ to show the strength of the association between KRAS mutation and objective response rate $(\mathrm{CR}+\mathrm{PR})$, and hazard ratios (HRs) with its $95 \%$ CIs to show the survival (OS, DFS or PFS) benefits of KRAS mutant tumors. The individual RRs and HRs were combined into pooled RR and HR, and the initial analyses were performed with a fixed effect model assuming homogeneity of the individual studies. Heterogeneity assumption was checked by Q-test and $I^{2}$ test. A significant Q-test $(p<0.05)$ or $I^{2}>50 \%$ indicate the heterogeneity among the studies, and the random-effect model was applied for meta-analysis.

Meta-regression analyses were generated to explore possible sources of heterogeneity (adjusted $\mathrm{R}^{2}>50 \%$ and $\mathrm{p}<0.05$ were consider significant).

Sensitivity analyses were conducted to identify whether results of the meta-analysis were signify affected by exclusion of any individual study and to testify the reliability of the conclusions.

Begg's and Egger's tests were used to evaluate the potential publication bias. The tests were considered statistically significant if $\mathrm{p}<0.05$, and a non-parametric "trim-and-fill" method was applied. All $p$ values were 2-sided and all analyses were performed using Stata SE 11.0 software.

\section{ACKNOWLEDGMENTS}

We thank Juejin Wang (Associate Professor, Department of Physiology, Nanjing Medical University) for the constructive comments on the revised manuscript.

\section{CONFLICTS OF INTEREST}

The authors have no conflict of interests to disclose.

\section{FUNDING}

This study was supported by grants from Natural Science Foundation of China (No. 81272504, 81472809), the Priority Academic Program Development of Jiangsu
Higher Education Institutions (PAPD) (JX10231801) and Key Academic Discipline of Jiangsu Province "Medical Aspects of Specific Environments".

\section{REFERENCES}

1. Jemal A, Bray F, Center MM, Ferlay J, Ward E and Forman D. Global cancer statistics. CA Cancer J Clin. 2011; 61:6990. doi: 10.3322/caac. 20107

2. Siegel R, DeSantis C, Virgo K, Stein K, Mariotto A, Smith T, Cooper D, Gansler T, Lerro C, Fedewa S, Lin C, Leach C, Cannady RS, et al. Cancer treatment and survivorship statistics, 2012. CA Cancer J Clin. 2014; 62:220-41. doi: 10.3322/caac.21149

3. Fukuoka M, Yano S, Giaccone G, Tamura T, Nakagawa K, Douillard J-Y, Nishiwaki Y, Vansteenkiste J, Kudoh S, Rischin D, Eek R, Horai T, Noda K, et al. Multi-institutional randomized phase II trial of gefitinib for previously treated patients with advanced non-small-cell lung cancer (The IDEAL 1 Trial) [corrected]. J Clin Oncol. 2003; 21 :223746. doi: 10.1200/JCO.2003.10.038

4. Rodenhuis S and Slebos RJ. The ras oncogenes in human lung cancer. Am Rev Respir Dis. 1990; 142:S27-30. doi: 10.1164/ajrccm/142.6_Pt_2.S27

5. Roberts PJ and Der CJ. Targeting the Raf-MEK-ERK mitogen-activated protein kinase cascade for the treatment of cancer. Oncogene. 2007; 26:3291-310. doi: 10.1038/ sj.onc. 1210422

6. Karachaliou N, Mayo C, Costa C and Magrí I. KRAS mutations in lung cancer. Clin Lung Cancer. 2013; 14:205-14. doi: 10.1016/j.cllc.2012.09.007

7. Slebos RJ, Kibbelaar RE, Dalesio O, Kooistra A, Stam J, Meijer CJ, Wagenaar SS, Vanderschueren RG, van Zandwijk $\mathrm{N}$ and Mooi WJ. K-ras oncogene activation as a prognostic marker in adenocarcinoma of the lung. N Engl J Med. 1990; 323:561-5. doi: 10.1056/ NEJM199008303230902

8. Eberhard DA, Johnson BE, Amler LC, Goddard AD, Heldens SL, Herbst RS, Ince WL, Jänne PA, Januario T, Johnson DH, Klein P, Miller VA, Ostland MA, et al. Mutations in the epidermal growth factor receptor and in KRAS are predictive and prognostic indicators in patients with non-small-cell lung cancer treated with chemotherapy alone and in combination with erlotinib. J Clin Oncol. 2005; 23:5900-9. doi: 10.1200/JCO.2005.02.857

9. Massarelli E, Varella-Garcia M, Tang X, Xavier AC, Ozburn NC, Liu DD, Bekele BN, Herbst RS and Wistuba II. $K R A S$ Mutation Is an Important Predictor of Resistance to Therapy with Epidermal Growth Factor Receptor Tyrosine Kinase Inhibitors in Non-Small-Cell Lung Cancer. Clinical Cancer Research. 2007; 13:2890-6. doi: 10.1158/10780432.CCR-06-3043

10. Kim HR, Shim HS, Chung J-H, Lee YJ, Hong YK, Rha SY, Kim SH, Ha S-J, Kim SK, Chung KY, Soo R, Kim $\mathrm{JH}$ and Cho BC. Distinct clinical features and outcomes in 
never-smokers with nonsmall cell lung cancer who harbor EGFR or KRAS mutations or ALK rearrangement. Cancer. 2011; 118:729-39. doi: 10.1002/cncr.26311

11. Metro G, Chiari R, Duranti S, Siggillino A, Fischer MJ, Giannarelli D, Ludovini V, Bennati C, Marcomigni L, Baldi A, Giansanti M, Minotti V and Crinò L. Impact of specific mutant KRAS on clinical outcome of EGFR-TKItreated advanced non-small cell lung cancer patients with an EGFR wild type genotype. Lung Cancer. 2012; 78:81-6. doi: 10.1016/j.lungcan.2012.06.005

12. Camps C, Jantus-Lewintre E, Cabrera A, Blasco A, Sanmartín E, Gallach S, Caballero C, del Pozo N, Rosell $\mathrm{R}$, Guijarro R and Sirera R. The identification of KRAS mutations at codon 12 in plasma DNA is not a prognostic factor in advanced non-small cell lung cancer patients. Lung Cancer. 2011; 72:365-9. doi: 10.1016/j. lungcan.2010.09.005

13. Nygaard AD, Garm Spindler K-L, Pallisgaard N, Andersen $\mathrm{RF}$ and Jakobsen A. The prognostic value of KRAS mutated plasma DNA in advanced non-small cell lung cancer. Lung Cancer. 2013; 79:312-7. doi: 10.1016/j. lungcan.2012.11.016

14. Mellema WW, Dingemans A-MC, Thunnissen E, Snijders PJF, Derks J, Heideman DAM, Van Suylen R and Smit EF. $K R A S$ mutations in advanced nonsquamous non-small-cell lung cancer patients treated with first-line platinum-based chemotherapy have no predictive value. J Thorac Oncol. 2013; 8:1190-5. doi: 10.1097/JTO.0b013e318298764e

15. Metro G, Chiari R, Bennati C, Cenci M, Ricciuti B, Puma F, Flacco A, Rebonato A, Giannarelli D, Ludovini V, Bellezza G, Ferolla P, Minotti V, et al. Clinical outcome with platinum-based chemotherapy in patients with advanced nonsquamous $E G F R$ wild-type non-small-cell lung cancer segregated according to KRAS mutation status. Clin Lung Cancer. 2014; 15:86-92. doi: 10.1016/j.cllc.2013.08.002

16. Marks JL, Broderick S, Zhou Q, Chitale D, Li AR, Zakowski MF, Kris MG, Rusch VW, Azzoli CG, Seshan VE, Ladanyi $\mathrm{M}$ and Pao W. Prognostic and therapeutic implications of EGFR and KRAS mutations in resected lung adenocarcinoma. J Thorac Oncol. 2008; 3:111-6. doi: 10.1097/JTO.0b013e318160c607

17. Zhu CQ, da Cunha Santos G, Ding K, Sakurada A, Cutz J-C, Liu N, Zhang T, Marrano P, Whitehead M, Squire JA, Kamel-Reid S, Seymour L, Shepherd FA, et al. Role of $K R A S$ and $E G F R$ as biomarkers of response to erlotinib in National Cancer Institute of Canada Clinical Trials Group Study BR.21. J Clin Oncol. 2008; 26:4268-75. doi: 10.1200/ JCO.2007.14.8924

18. Pesek M, Benesova L, Belsanova B, Mukensnabl P, Bruha $\mathrm{F}$ and Minarik M. Dominance of EGFR and insignificant $K R A S$ mutations in prediction of tyrosine-kinase therapy for NSCLC patients stratified by tumor subtype and smoking status. Anticancer Res. 2009; 29:2767-73.

19. Jackman DM, Miller VA, Cioffredi L-A, Yeap BY, Jänne PA, Riely GJ, Ruiz MG, Giaccone G, Sequist LV and
Johnson BE. Impact of Epidermal Growth Factor Receptor and KRAS Mutations on Clinical Outcomes in Previously Untreated Non-Small Cell Lung Cancer Patients: Results of an Online Tumor Registry of Clinical Trials. Clin Cancer Res. 2009; 15:5267-73. doi: 10.1158/1078-0432. CCR-09-0888

20. Liu H-P, Isaac Wu H-D, Chang JW-C, Wu Y-C, Yang H-Y, Chen Y-T, Hsieh W-Y, Chen Y-T, Chen Y-R and Huang S-F. Prognostic implications of epidermal growth factor receptor and KRAS gene mutations and epidermal growth factor receptor gene copy numbers in patients with surgically resectable non-small cell lung cancer in Taiwan. J Thorac Oncol. 2010; 5:1175-84. doi: 10.1097/ JTO.0b013e3181e2f4d6

21. Ludovini V, Bianconi F, Pistola L, Chiari R, Minotti V, Colella R, Giuffrida D, Tofanetti FR, Siggillino A, Flacco A, Baldelli E, Iacono D, Mameli MG, et al. Phosphoinositide3-kinase catalytic alpha and $K R A S$ mutations are important predictors of resistance to therapy with epidermal growth factor receptor tyrosine kinase inhibitors in patients with advanced non-small cell lung cancer. J Thorac Oncol. 2011; 6:707-15. 10.1097/JTO.0b013e31820a3a6b

22. Brugger W, Triller N, Blasinska-Morawiec M, Curescu S, Sakalauskas R, Manikhas GM, Mazieres J, Whittom R, Ward C, Mayne K, Trunzer K and Cappuzzo F. Prospective molecular marker analyses of EGFR and KRAS from a randomized, placebo-controlled study of erlotinib maintenance therapy in advanced non-small-cell lung cancer. J Clin Oncol. 2011; 29:4113-20. doi: 10.1200/JCO.2010.31.8162

23. Johnson ML, Sima CS, Chaft J, Paik PK, Pao W, Kris MG, Ladanyi $\mathrm{M}$ and Riely GJ. Association of KRAS and EGFR mutations with survival in patients with advanced lung adenocarcinomas. Cancer. 2012; 119:356-62. doi: 10.1002/ cncr. 27730

24. Ragusa M, Vannucci J, Ludovini V, Bianconi F, Treggiari S, Tofanetti FR, Flacco A, Colella R, Sidoni A, Crinò L and Puma F. Impact of epidermal growth factor receptor and KRAS mutations on clinical outcome in resected non-small cell lung cancer patients. American Journal of Clinical Oncology. 2014; 37:343-9. doi:10.1097/ COC.0b013e31827a7e7a

25. Shepherd FA, Domerg C, Hainaut P, Jänne PA, Pignon J-P, Graziano S, Douillard J-Y, Brambilla E, Le Chevalier T, Seymour L, Bourredjem A, Le Teuff G, Pirker R, et al. Pooled analysis of the prognostic and predictive effects of $K R A S$ mutation status and KRAS mutation subtype in earlystage resected non-small-cell lung cancer in four trials of adjuvant chemotherapy. J Clin Oncol. 2013; 31:2173-81. doi: 10.1200/JCO.2012.48.1390

26. Kerner GSMA, Schuuring E, Sietsma J, Hiltermann TJN, Pieterman RM, de Leede GPJ, van Putten JWG, Liesker J, Renkema TEJ, van Hengel P, Platteel I, Timens W and Groen HJM. Common and Rare EGFR and KRAS Mutations in a Dutch Non-Small-Cell Lung Cancer Population and Their Clinical Outcome. PLoS ONE. 2013; 8:e70346. doi: 10.1371/journal.pone.0070346 
27. Macerelli M, Caramella C, Faivre L, Besse B, Planchard D, Polo V, Ngo Camus M, Celebic A, Koubi-Pick V, Lacroix L, Pignon JP and Soria JC. Does KRAS mutational status predict chemoresistance in advanced non-small cell lung cancer (NSCLC)? Lung Cancer. 2014; 83:383-8. doi: 10.1016/j.lungcan.2013.12.013

28. Cserepes M, Ostoros G, Lohinai Z, Raso E, Barbai T, Timar J, Rozsas A, Moldvay J, Kovalszky I, Fabian K, Gyulai M, Ghanim B, Laszlo V, et al. Subtype-specific KRAS mutations in advanced lung adenocarcinoma: a retrospective study of patients treated with platinum-based chemotherapy. Eur J Cancer. 2014; 50:1819-28. doi: 10.1016/j. ejca.2014.04.001

29. Kim YT, Kim T-Y, Lee DS, Park SJ, Park J-Y, Seo S-J, Choi H-S, Kang HJ, Hahn S, Kang CH, Sung SW and Kim JH. Molecular changes of epidermal growth factor receptor (EGFR) and KRAS and their impact on the clinical outcomes in surgically resected adenocarcinoma of the lung. Lung Cancer. 2008; 59:111-8. doi: 10.1016/j. lungcan.2007.08.008

30. Woo T, Okudela K, Yazawa T, Wada N, Ogawa N, Ishiwa N, Tajiri M, Rino Y, Kitamura $\mathrm{H}$ and Masuda M. Prognostic value of $K R A S$ mutations and $\mathrm{Ki}-67$ expression in stage I lung adenocarcinomas. Lung Cancer. 2009; 65:355-62. doi: 10.1016/j.lungcan.2008.11.020

31. Cadranel J, Mauguen A, Faller M, Zalcman G, Buisine M-P, Westeel V, Longchampt E, Wislez M, Coudert B, Daniel C, Chetaille B, Michiels S, Blons H, et al. Impact of systematic EGFR and KRAS mutation evaluation on progression-free survival and overall survival in patients with advanced non-small-cell lung cancer treated by erlotinib in a French prospective cohort (ERMETIC projectpart 2). J Thorac Oncol. 2012; 7:1490-502. doi: 10.1097/ JTO.0b013e318265b2b5

32. Guan J-L, Zhong W-Z, An S-J, Yang J-J, Su J, Chen Z-H, Yan H-H, Chen Z-Y, Huang Z-M, Zhang X-C, Nie Q and Wu Y-L. KRAS mutation in patients with lung cancer: a predictor for poor prognosis but not for EGFR-TKIs or chemotherapy. Ann Surg Oncol. 2013; 20:1381-8. doi: 10.1245/ s10434-012-2754-z

33. Maemondo M, Inoue A, Kobayashi K, Sugawara S, Oizumi S, Isobe H, Gemma A, Harada M, Yoshizawa H and Kinoshita I. Gefitinib or chemotherapy for non-smallcell lung cancer with mutated EGFR. N Engl J Med. 2010; 362:2380-8. doi: 10.1056/NEJMoa0909530

34. Sun J-M, Hwang DW, Ahn JS, Ahn M-J and Park K. Prognostic and Predictive Value of KRAS Mutations in Advanced Non-Small Cell Lung Cancer. PLoS ONE. 2013; 8:e64816. doi: 10.1371/journal.pone.0064816

35. Pao W, Wang TY, Riely GJ, Miller VA, Pan Q, Ladanyi M, Zakowski MF, Heelan RT, Kris MG and Varmus HE. KRAS Mutations and Primary Resistance of Lung Adenocarcinomas to Gefitinib or Erlotinib. Plos Med. 2005; 2:e17. doi: 10.1371/journal.pmed.0020017
36. Dogan S, Shen R, Ang DC, Johnson ML, D'Angelo SP, Paik PK, Brzostowski EB, Riely GJ, Kris MG, Zakowski MF and Ladanyi M. Molecular epidemiology of EGFR and $K R A S$ mutations in 3,026 lung adenocarcinomas: higher susceptibility of women to smoking-related $K R A S$-mutant cancers. Clin Cancer Res. 2012; 18:6169-77. doi: 10.4999/ uhod. 13083

37. Boch C, Kollmeier J, Roth A, Stephan-Falkenau S, Misch D, Gruning W, Bauer TT and Mairinger T. The frequency of $E G F R$ and KRAS mutations in non-small cell lung cancer (NSCLC): routine screening data for central Europe from a cohort study. BMJ Open. 2013; 3:e002560-0. doi: 10.1136/ bmjopen-2013-002560

38. Gautschi O, Huegli B, Ziegler A, Gugger M, Heighway J, Ratschiller D, Mack PC, Gumerlock PH, Kung HJ, Stahel RA, Gandara DR and Betticher DC. Origin and prognostic value of circulating $K R A S$ mutations in lung cancer patients. Cancer Lett. 2007; 254:265-73. doi: 10.1016/j. canlet.2007.03.008

39. Kosaka T, Yatabe Y, Onozato R, Kuwano H and Mitsudomi T. Prognostic implication of EGFR, KRAS, and TP53 gene mutations in a large cohort of Japanese patients with surgically treated lung adenocarcinoma. J Thorac Oncol. 2009; 4:22-9. doi: 10.1097/JTO.0b013e3181914111

40. Marchetti A, Milella M, Felicioni L, Cappuzzo F, Irtelli L, Del Grammastro M, Sciarrotta M, Malatesta S, Nuzzo C, Finocchiaro G, Perrucci B, Carlone D, Gelibter AJ, et al. Clinical implications of $K R A S$ mutations in lung cancer patients treated with tyrosine kinase inhibitors: an important role for mutations in minor clones. Neoplasia. 2009; 11:1084-92.

41. Bonanno L, Schiavon M, Nardo G, Bertorelle R, Bonaldi L, Galligioni A, Indraccolo S, Pasello G, Rea F and Favaretto A. Prognostic and predictive implications of EGFR mutations, EGFR copy number and KRAS mutations in advanced stage lung adenocarcinoma. Anticancer Res. 2010; 30:5121-8.

42. Ludovini V, Bianconi F, Pistola L, Pistola V, Chiari R, Colella R, Bellezza G, Tofanetti FR, Siggillino A, Baldelli E, Flacco A, Giuffrida D, Sidoni A, et al. Optimization of patient selection for EGFR-TKIs in advanced non-small cell lung cancer by combined analysis of KRAS, PIK3CA, $M E T$, and non-sensitizing EGFR mutations. Cancer Chemother Pharmacol. 2012; 69:1289-99. doi: 10.1007/ s00280-012-1829-7

43. Scoccianti C, Vesin A, Martel G, Olivier M, Brambilla E, Timsit JF, Tavecchio L, Brambilla C, Field JK and Hainaut P. Prognostic value of TP53, KRAS and EGFR mutations in nonsmall cell lung cancer: the EUELC cohort. European Respiratory Journal. 2012; 40:177-84. doi: 10.1183/09031936.00097311

44. Gao J, Chen J-Q, Zhang L and Liang Z-Y. Relationship between EGFR and KRAS mutations and prognoisis in Chinese patients with non-small cell lung cancer: a 
mutation analysis with real-time polymerase chain reaction using scropion amplification refractory mutation system. Zhonghua Bing Li Xue Za Zhi. 2012; 41:652-6. doi: 10.3760/cma.j.issn.0529-5807.2012.10.002

45. Kim ST, Sung JS, Jo UH, Park KH, Shin SW and Kim YH. Can mutations of EGFR and KRAS in serum be predictive and prognostic markers in patients with advanced non-small cell lung cancer (NSCLC)? Med Oncol. 2013; 30:328-10. doi: 10.1007/s12032-012-0328-3

46. Fiala O, Pesek M, Finek J, Benesova L, Bortlicek Z and Minarik M. Gene mutations in squamous cell NSCLC: insignificance of EGFR, KRAS and PIK3CA mutations in prediction of EGFR-TKI treatment efficacy. Anticancer Res. 2013; 33:1705-11.

47. Izar B, Zhou H, Heist RS, Azzoli CG, Muzikansky A, Scribner EEF, Bernardo LA, Dias-Santagata D, Iafrate AJ and Lanuti M. The prognostic impact of $K R A S$, its codon and amino acid specific mutations, on survival in resected stage I lung adenocarcinoma. J Thorac Oncol. 2014; 9:1363-9. doi: 10.1097/JTO.0000000000000266

48. Nadal E, Beer DG, Ramnath N. KRAS-G12C mutation is associated with poor outcome in surgically resected lung adenocarcinoma. J Thorac Oncol. 2015; 10:e9-10. doi: 10.1097/JTO.0000000000000438

49. Campos-Parra AD, Zuloaga C, Manríquez MEV, Avilés A, Borbolla-Escoboza J, Cardona A, Meneses A and Arrieta O. KRAS mutation as the biomarker of response to chemotherapy and EGFR-TKIs in patients with advanced non-small cell lung cancer: clues for its potential use in second-line therapy decision making. American Journal of Clinical Oncology. 2015; 38:33-40. doi: 10.1097/ COC.0b013e318287bb23

50. Yagishita S, Horinouchi H, Sunami KS, Kanda S, Fujiwara Y, Nokihara H, Yamamoto N, Sumi M, Shiraishi K, Kohno $\mathrm{T}$, Furuta K, Tsuta K, Tamura T, et al. Impact of KRAS mutation on response and outcome of patients with stage III non-squamous non-small cell lung cancer. Cancer Sci. 2015; 106:1402-07. doi: 10.1111/cas.12740

51. Rulli E, Marabese M, Torri V, Farina G, Veronese S, Bettini A, Longo F, Moscetti L, Ganzinelli M, Lauricella C, Copreni E, Labianca R, Martelli O, et al. Value of $K R A S$ as prognostic or predictive marker in NSCLC: results from the TAILOR trial. Ann Oncol. 2015; 26:2079-84. doi: 10.1093/ annonc/mdv318

52. Riely GJ, Marks J and Pao W. KRAS mutations in non-small cell lung cancer. Proc Am Thorac Soc. 2009; 6:201-5. doi: 10.1513/pats.200809-107LC

53. Brose MS, Volpe P, Feldman M, Kumar M, Rishi I, Gerrero R, Einhorn E, Herlyn M, Minna J, Nicholson A, Roth JA, Albelda SM, Davies H, et al. BRAF and RAS mutations in human lung cancer and melanoma. Cancer Res. 2002; 62:6997-7000.

54. Allegra CJ, Jessup JM, Somerfield MR, Hamilton SR, Hammond EH, Hayes DF, McAllister PK, Morton RF and
Schilsky RL. American Society of Clinical Oncology provisional clinical opinion: testing for KRAS gene mutations in patients with metastatic colorectal carcinoma to predict response to anti-epidermal growth factor receptor monoclonal antibody therapy. J Clin Oncol. 2009;27:2091-6. doi: 10.1200/JCO.2009.21.9170

55. Mascaux C, Iannino N, Martin B, Paesmans M, Berghmans T, Dusart M, Haller A, Lothaire P, Meert A-P, Noel S, Lafitte J-J and Sculier J-P. The role of $R A S$ oncogene in survival of patients with lung cancer: a systematic review of the literature with meta-analysis. Br J Cancer. 2004; 92:131-9. doi: 10.1038/sj.bjc.6602258

56. Mao C, Qiu L-X, Liao R-Y, Du F-B, Ding H, Yang W-C, $\mathrm{Li} \mathrm{J}$ and Chen Q. KRAS mutations and resistance to EGFRTKIs treatment in patients with non-small cell lung cancer: A meta-analysis of 22 studies. Lung Cancer. 2010; 69:2728. doi: 10.1016/j.lungcan.2009.11.020

57. Ying M, Zhu X, Chen K, Sha Z and Chen L. Should KRAS mutation still be used as a routine predictor of response to EGFR-TKIs in advanced non-small-cell lung cancer? A revaluation based on meta-analysis. J Cancer Res Clin Oncol. 2015; 141:1427-39. doi: 10.1007/ s00432-015-1910-9

58. Zhang Y, Fang W, Yan Y, Wang M, Kang S, Sheng J, Zhan J, Chen N, Hong S, Yang Y, Ma Y, He D, Qin T, et al. The efficacy of first-line chemotherapy is associated with $K R A S$ mutation status in patients with advanced non-small cell lung cancer: a meta-analysis. Med Oncol. 2015; 32:61. doi: 10.1007/s12032-015-0489-y

59. Fiala O, Pesek M, Finek J, Benesova L, Belsanova B and Minarik M. The dominant role of $\mathrm{G} 12 \mathrm{C}$ over other KRAS mutation types in the negative prediction of efficacy of epidermal growth factor receptor tyrosine kinase inhibitors in non-small cell lung cancer. Cancer Genet. 2013; 206:26-31. doi: 10.1016/j.cancergen.2012.12.003

60. Li S, Li L, Zhu Y, Huang C, Qin Y, Liu H, Ren-Heidenreich L, Shi B, Ren H, Chu X, Kang J, Wang W, Xu J, et al. Coexistence of EGFR with KRAS, or BRAF, or PIK3CA somatic mutations in lung cancer: a comprehensive mutation profiling from 5125 Chinese cohorts. Br J Cancer. 2014; 110:2812-20. doi: 10.1038/bjc.2014.210

61. Garassino MC, Marabese M, Rusconi P, Rulli E, Martelli O, Farina G, Scanni A and Broggini M. Different types of $K$-Ras mutations could affect drug sensitivity and tumour behaviour in non-small-cell lung cancer. Ann Oncol. 2011; 22:235-7. doi: 10.1093/annonc/mdq680

62. Dingemans A-MC, Mellema WW, Groen HJM, van Wijk A, Burgers SA, Kunst PWA, Thunnissen E, Heideman DAM and Smit EF. A phase II study of sorafenib in patients with platinum-pretreated, advanced (Stage IIIb or IV) non-small cell lung cancer with a KRAS mutation. Clin Cancer Res. 2013; 19:743-51. doi: 10.1158/1078-0432.CCR-12-1779

63. Metro G, Chiari R, Baldi A, De Angelis V, Minotti V and Crinò L. Selumetinib: a promising pharmacologic approach 
for $K R A S$-mutant advanced non-small-cell lung cancer. Future Oncol. 2013; 9:167-77. doi:10.2217/fon.12.198

64. Said R, Ye Y, Falchook GS, Janku F, Naing A, Zinner R, Blumenschein GR, Fu S, Hong DS, Piha-Paul SA, Wheler JJ, Kurzrock R, Palmer GA, et al. Outcomes of patients with advanced cancer and KRAS mutations in phase I clinical trials. Oncotarget. 2014; 5:8937-46. doi: 10.18632/ oncotarget.2339

65. Hara T, Jones MF, Subramanian M, Li XL, Ou O, Zhu Y, Yang Y, Wakefield LM, Hussain SP, Gaedcke J, Ried T,
Luo J, Caplen NJ, et al. Selective targeting of KRAS-mutant cells by miR-126 through repression of multiple genes essential for the survival of $K R A S$-mutant cells. Oncotarget. 2014; 5:7635-50. doi: 10.18632/oncotarget.2339

66. Tierney JF, Stewart LA, Ghersi D, Burdett S and Sydes MR. Practical methods for incorporating summary timeto-event data into meta-analysis. Trials. 2007; 8:16. doi:10.1186/1745-6215-8-16 